\title{
With great (participant) rights comes great (researcher) responsibility
}

\author{
Gail E. Henderson, $\mathrm{PhD}^{1}$
}

Are we worrying too much about privacy risks in genomic research? Should we be focusing instead on telling participants about their right to participate in research, to contribute to the advancement of science and ultimately medicine? This view, expressed at an American College of Medical Genetics and Genomics (ACMG) Q\&A session, drew spontaneous applause from an audience of more than 1,000 members.

What did this signify? Support for a startling endorsement of public entitlement to participate in research? Or just fatigue over worrying about research privacy, especially when many view "informational risks" from genomic research participation to be exceedingly low? ${ }^{1}$ Or was it a reaction to the specific challenge of securing genomic research access to clinical information about patients-information that is usually protected by traditional commitments to the patient's best interests?

Of course, risk to privacy differs depending on the research context. Huge "big data" sequencing studies may be an excellent example of low-risk/high-benefit research, because knowledge about very rare variants can only be confirmed by collecting genomic information from a very large number of individuals whose identity can reasonably be protected, and because such research has the potential to considerably advance knowledge of human disease. Yet case-level data are also needed to complete and confirm forecasts of pathogenicity, and that will require phenotypic data, for which the best source will be electronic medical records of people like you and me. In these studies, risks to privacy may be greater and more difficult to protect.

People participate in genomic research for many reasons, with a range of expectations about privacy. It is well documented that privacy is an important issue for individuals when considering sharing personal information online. ${ }^{2}$ Yet some research participants are willing to divulge information that would normally be considered private, like clinical records, and take social risks in doing so. In fact, studies have shown that, when asked, people will often consent to broad uses of their DNA and associated personal data. ${ }^{3}$ Two aspects are key: privacy of genetic identity is one consideration, and privacy of personal health information-only some uses of which are protected by GINA - is another. It is essential that both be addressed, and thus many genetic studies are designed to give participants as much control over the risks of reidentification as possible.
But even when it becomes impossible to "de-identify" data in genomic research, some individuals-called "health information altruists" they consider themselves socially safe enough to do so.

Yet, how does this imply a right to participation? There is no legal basis for individuals to claim a right to be research subjects in any particular research study. Furthermore, as Arlene Davis, JD, writes, "There are long-standing and sound arguments in law and practical ethics about what invocation of 'rights' language does to conversations. It does not seem to permit focus on the concern related to the claimed right, but instead motivates a defensive posture. That is, the person claiming the right demands either assistance in obtaining the right or a lack of interference from the other. Thus, rights language often seems inflammatory rather than helpful" (personal communication, 28 March 2015).

Its impact certainly drew audience reaction at the ACMG session. A rhetorical use of rights language refocuses attention from privacy risks and toward promoting more information altruism among patients and toward the goal of scientific progress to which participants could "rightfully" contribute. If patients are willing to become information altruists to help researchers achieve benefits to society (and to future patients, family members, or even themselves), ${ }^{5}$ then the corresponding obligation on the part of researchers, which invocation of rights language should motivate, is to make every effort to ensure that research using personal information and samples will in fact yield those benefits. ${ }^{6}$

Some might argue that we are experiencing a significant shift in research roles and relationships, undermining traditional expectations and behaviors, and new language is needed. From one direction, the National Institutes of Health's Clinical and Translational Science Awards place a strong emphasis on initiation of community engagement at the earliest stages to speed the translational process. From another, the "citizen science" movement ${ }^{7}$ and lay advocacy organizations such as Genetic Alliance or the recent Google partnership with autism families encourage the transformation of "subjects" into full "partners" in science. There are also exciting Web-based opportunities such as my46.org for participants to monitor studies or select the kind of research results they or their children would like

${ }^{1}$ Department of Social Medicine, UNC School of Medicine, Chapel Hill, North Carolina, USA. Correspondence: Gail E. Henderson (gail_henderson@med.unc.edu)

Submitted 11 April 2015; accepted 13 April 2015; advance online publication 7 May 2015. doi:10.1038/gim.2015.67 
returned. However, the shifting environment has produced overlapping terms and concepts enthusiastically used in all these efforts that are often imprecise. ${ }^{8}$ What kinds of "participation" are we seeking to protect, what "rights" are we seeking to promote, and for whom? Active involvement in protocol design and monitoring? Control over data-sharing and a voice in data interpretation? Is it just for patients, or is it for other individuals and communities, too? And what "obligations" are owed to those whose "rights" we will protect?

There is great scientific promise in genomics, in deciphering the genome, and in creating data-sharing networks across laboratories, researchers, and patients, nationally and internationally. Unfortunately, although many researchers and networks may intend to collect and share research resources wisely and productively, ${ }^{9}$ the reality is far more complex and challenging. In our 2012 national survey of 456 US biobank managers, we found that two-thirds reported underutilization of specimens and associated data to be a major concern. In fact, it was listed as the second most significant challenge for biobanks after securing funding. To maintain public trust in science, and to realize the vision of "big data" and "big science," this reality must be acknowledged as both a practical and an ethical concern.

Many individuals will express their "right" to participate in research by taking leadership roles with genome scientists. We should join in applauding the rise of such information altruists who are willing to take social risks to realize such endeavors. Yet, other research participants will be less inclined to take such an active role and will rely more on the stewardship provided by researchers, community or scientific advisory boards, and institutional review boards to offer both protection and the promise of research value in the future. ${ }^{10} \mathrm{I}$ suggest that it is critical to consider how to give meaning to the right to participate, by balancing protection with engagement and ensuring that the altruism of genomic research participants is repaid with research that can deliver on the promises of that vision. Participants may have a right to participate in research, but they also certainly have the right to expect that their participation is put to good scientific use.

\section{ACKNOWLEDGMENTS}

Helpful suggestions were provided by the following colleagues: Arlene Davis, Jean Cadigan, Jim Evans, Eric Juengst, Cynthia Khan, Anya Prince, Kelly Raspberry, Heidi Rehm, and Debra Skinner.

\section{DISCLOSURE}

The author declares no conflict of interest.

\section{REFERENCES}

1. Cadigan RJ, Nelson DK, Henderson GE, Nelson AG, Davis AM. Public comments on proposed regulatory reforms that would impact biospecimen research: the good, the bad and the puzzling. IRB Ethics Hum Res, in press.

2. Pew Research Center. Online Privacy and Safety. http://www.pewresearch.org/ topics/privacy-and-safety/pages/3/. Accessed 8 April 15.

3. Ludman EJ, Fullerton SM, Spangler L, et al. Glad you asked: participants' opinions of re-consent for dbGap data submission. J Empir Res Hum Res Ethics 2010;5:9-16.

4. Kohane IS, Altman RB. Health-information altruists-a potentially critical resource. N Engl J Med 2005;353:2074-2077.

5. Haase R, Michie M, Skinner D. Flexible positions, managed hopes: the promissory bioeconomy of a whole genome sequencing cancer study. Soc Sci Med 2015;130:146-153.

6. Knoppers B. Framework for responsible sharing of genomic and health-related data. HUGO J 2014;8:3. http://www.thehugojournal.com/content/8/1/3. Accessed 10 April 2015.

7. Citizen Science Alliance. http://www.citizensciencealliance.org/projects.html Accessed 8 April 15

8. Haldeman KM, Cadigan RJ, Davis A, et al. Community engagement in US biobanking: multiplicity of meaning and method. Public Health Genomics 2014;17:84-94.

9. Cadigan RJ, Juengst E, Davis A, Henderson G. Underutilization of specimens in biobanks: an ethical as well as a practical concern? Genet Med 2014;16:738-740.

10. Henderson GE, Edwards TP, Cadigan RJ, et al. Stewardship practices of U.S. biobanks. Sci Trans/ Med 2013;5:215cm7. 